\title{
Mulheres e política: imagens de gênero e resistência
}

\author{
Ramiro Gabriel Garcia ${ }^{1}$ \\ Henrique da Costa Valério Quagliato ${ }^{2}$
}

\begin{abstract}
No dia 11 de março deste ano, o Instituto Política Por.De.Para Mulheres promoveu, no Teatro da Reitoria da UFPR, o lançamento do livro Gênero e Resistência (2019). O volume é fruto das pesquisas apresentadas no II Encontro de Pesquisa Por.De.Para Mulheres, realizado em 2018. Para participar do evento, foram convidadas Manuela D'Ávila, candidata à vice-presidência da República nas eleições do ano passado, e Diva Guimarães, professora paranaense que ganhou repercussão nacional após falar a respeito do preconceito racial durante a Feira Literária de Paraty, em 2017.

O arranjo de fotografias a seguir, realizado por Henrique da Costa Valério Quagliato, retrata o evento por meio das lentes de Ramiro Gabriel Garcia, fotógrafo e doutorando do Programa de Pós-Graduação em Sociologia da UFPR. Convidado pela Revista Sociologias Plurais, Garcia teve acesso à entrevista com as convidadas nos bastidores, às falas e aos debates promovidos ao longo do evento.
\end{abstract}

${ }^{1}$ Bolsista CAPES, é aluno do doutorado do Programa de Pós-Graduação em Sociologia da Universidade Federal do Paraná. Email: ramirogabrielgarcia@gmail.com.

${ }^{2}$ Bolsista CAPES, discente do Programa de Pós-graduação em Sociologia da Universidade Federal do Paraná. E-mail: hcvq@hotmail.com. 


\section{Mulheres e política: imagens de gênero e resistência}

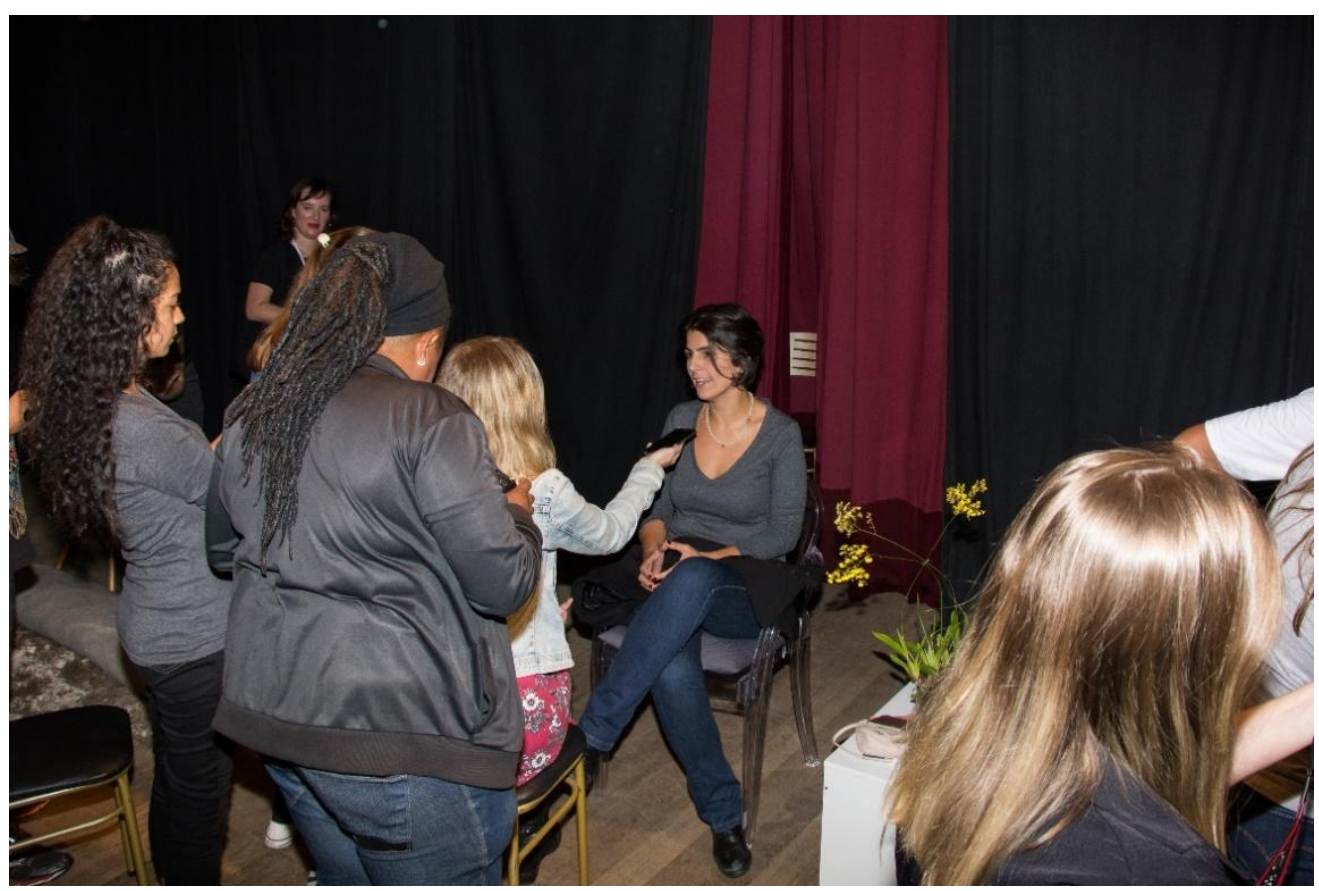

Manuela D'Ávila nos bastidores do evento "Gênero e Resistência".

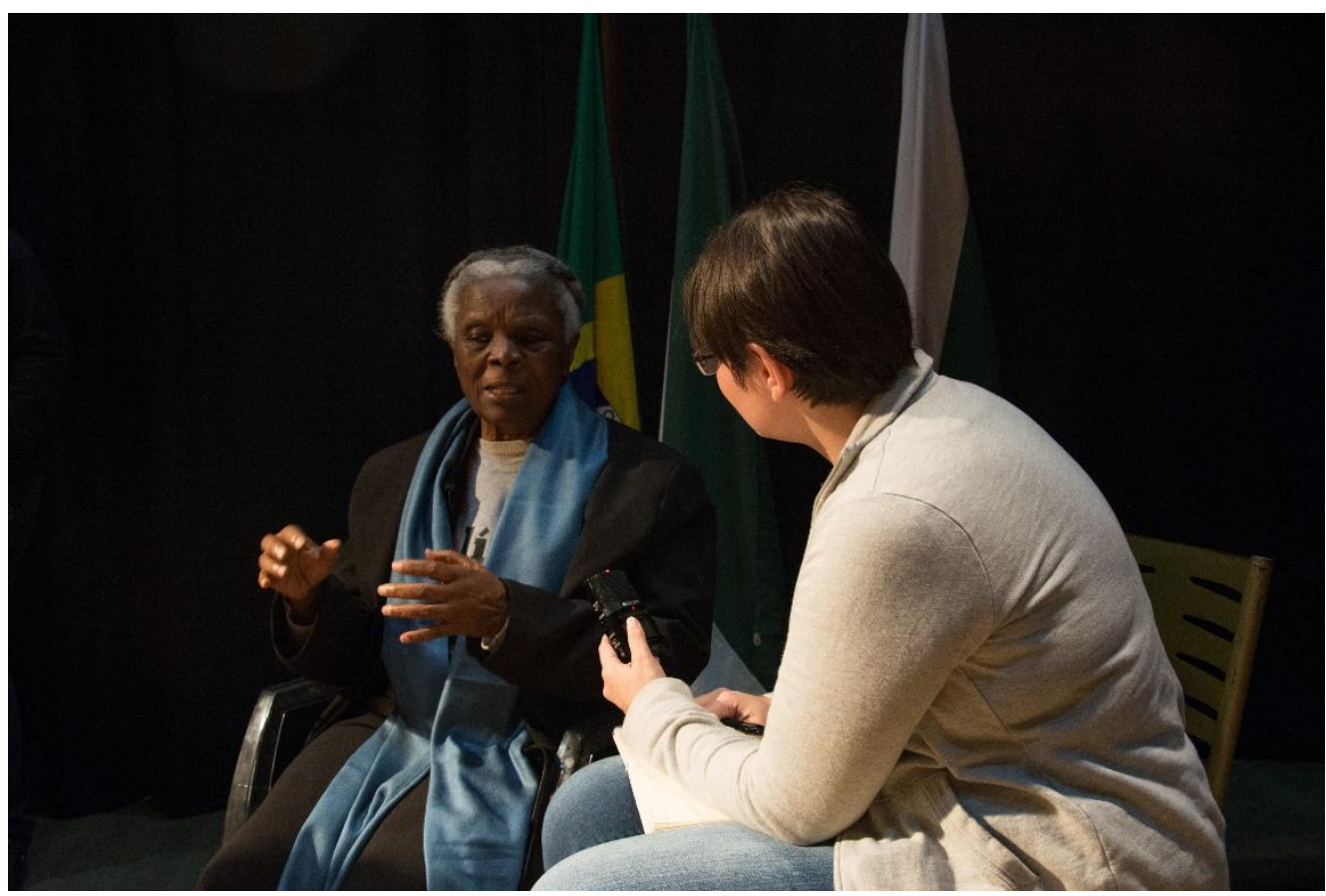

Entrevista com Diva Guimarães nos bastidores do evento.

Rev. Sociologias Plurais, v. 5, n. 1, p. 41-51, jul. 2019 


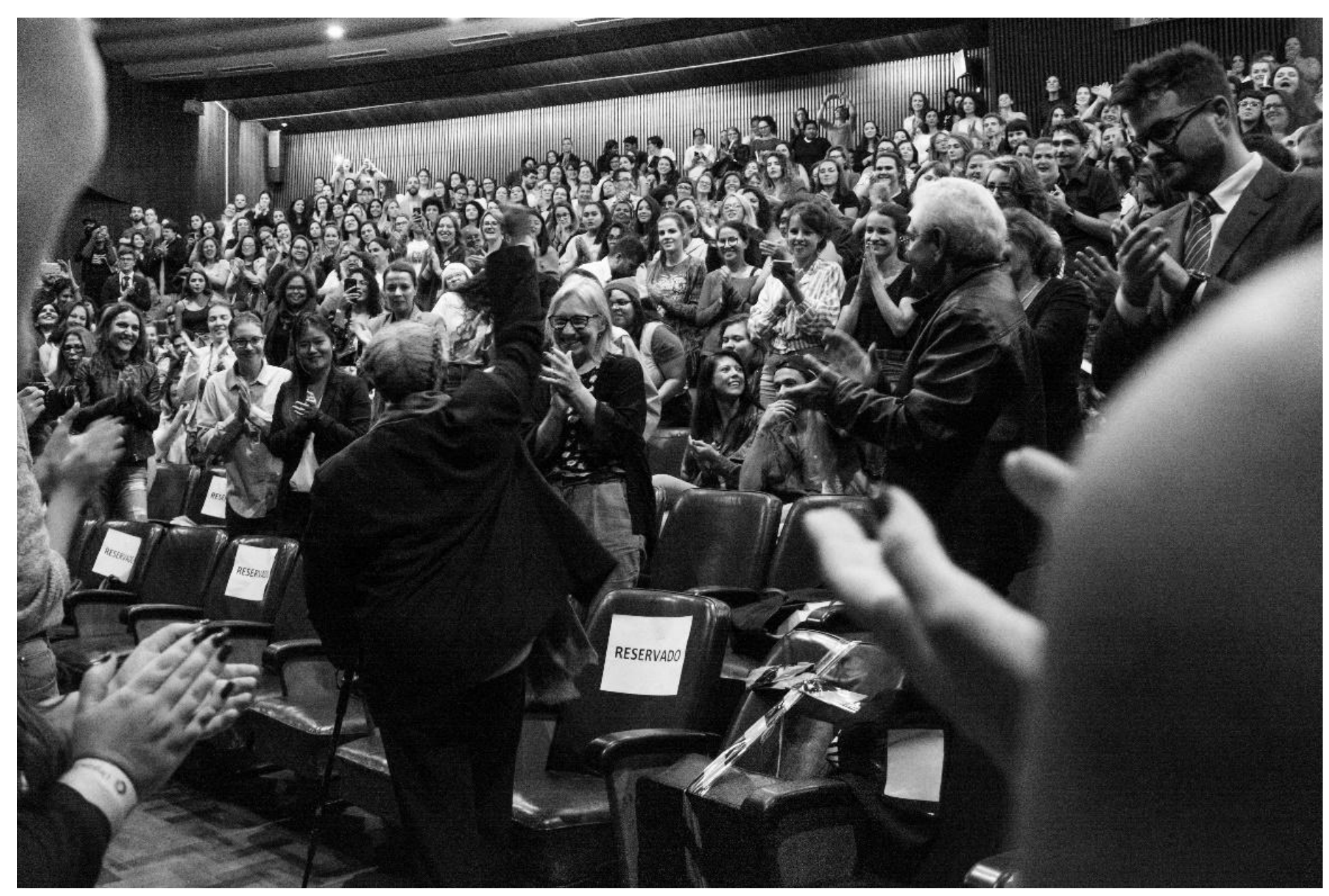

Recepção calorosa para Diva Guimarães. 


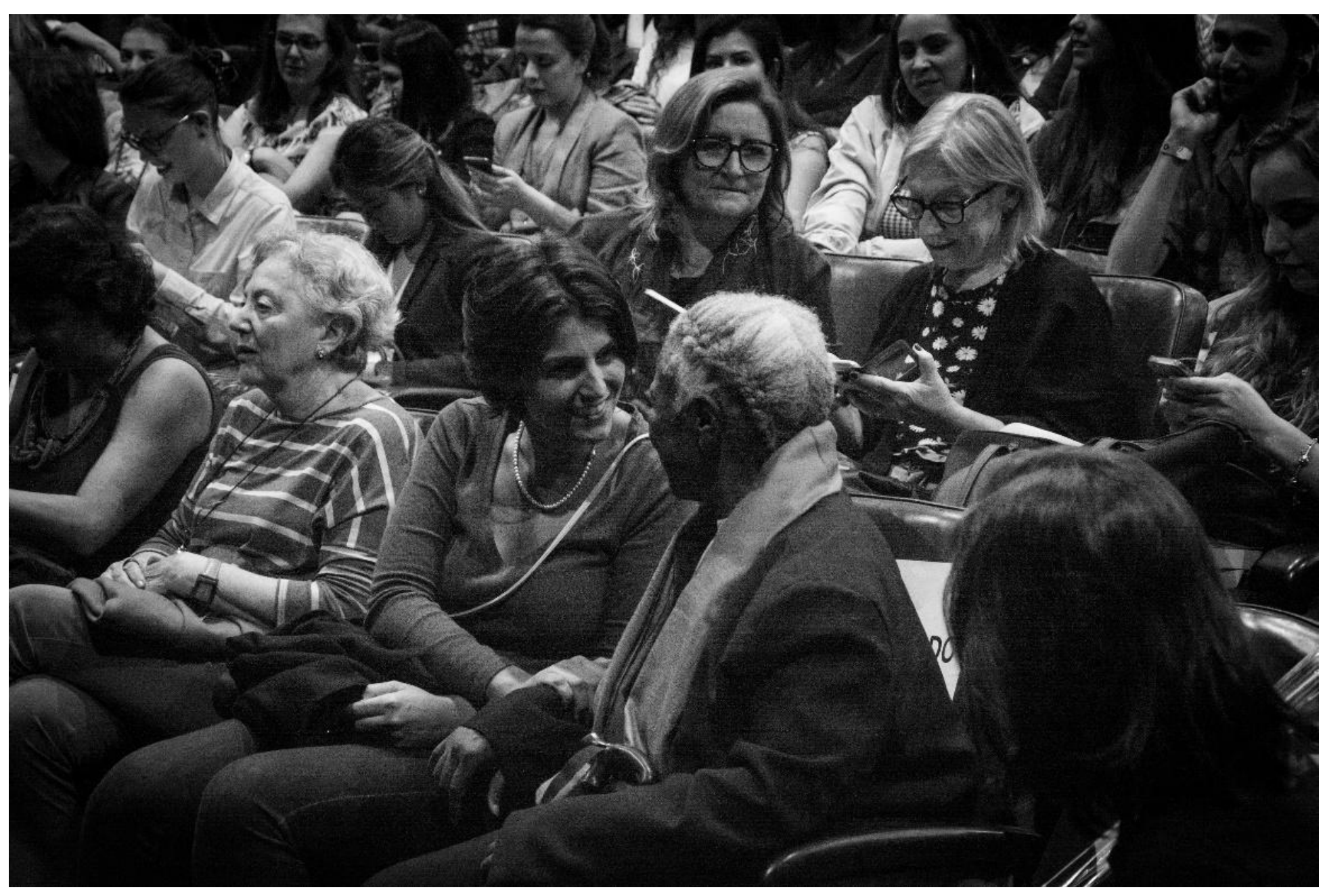

Na plateia, logo antes do início das atividades: Manuela D'Ávila e Diva Guimarães. 


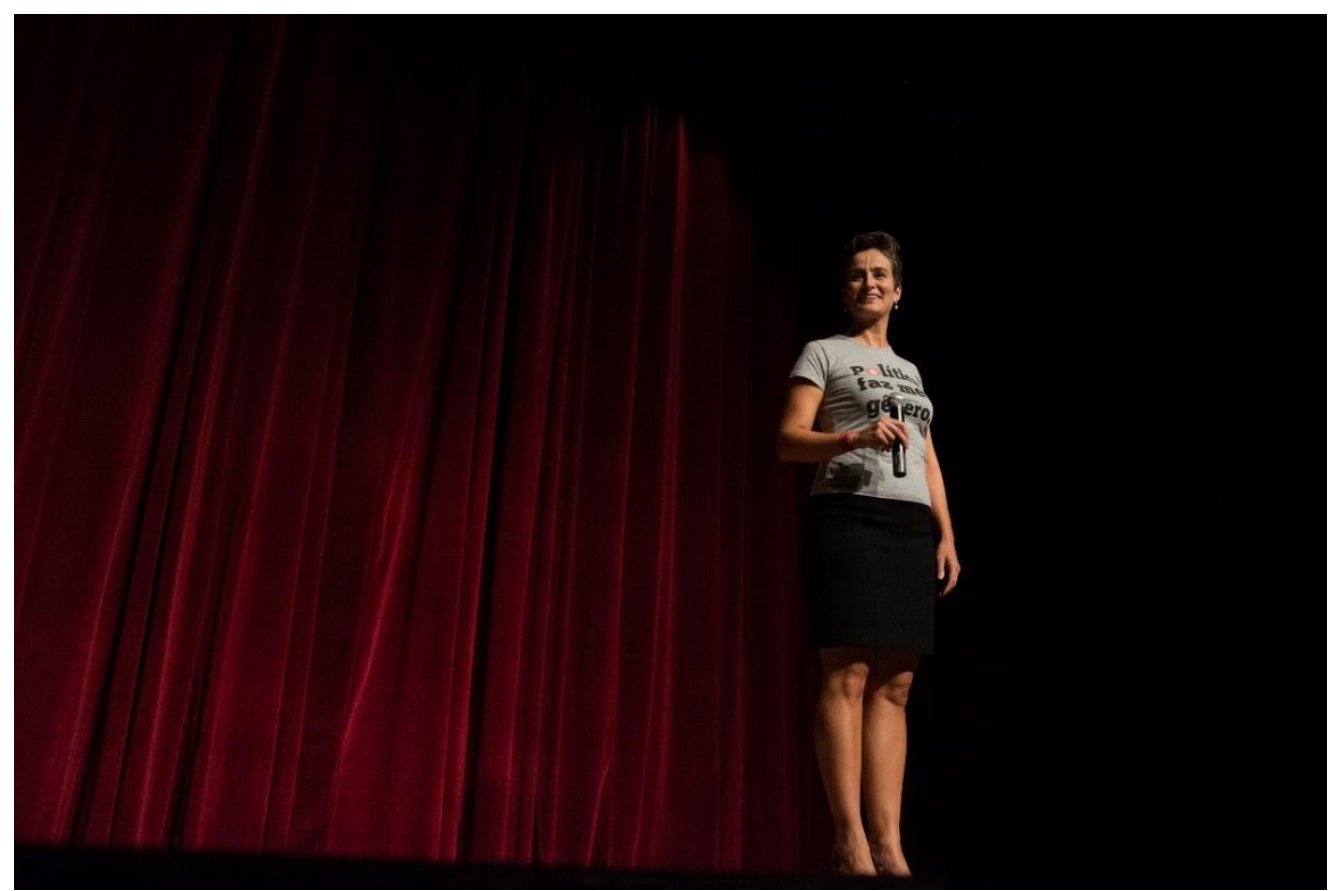

Professora Eneida Desiree Salgado.

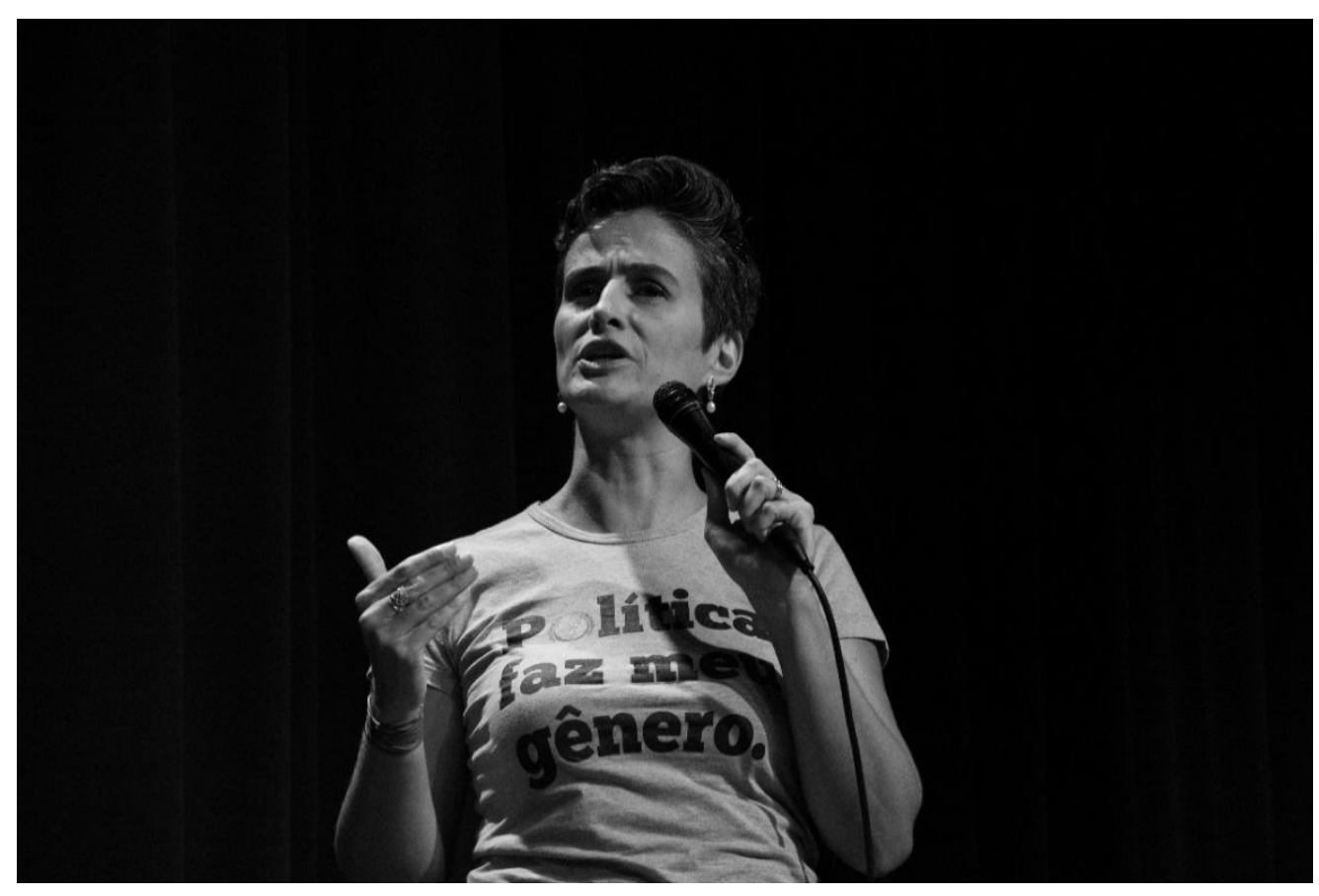

Política faz meu gênero.

Rev. Sociologias Plurais, v. 5, n. 1, p. 41-51, jul. 2019 


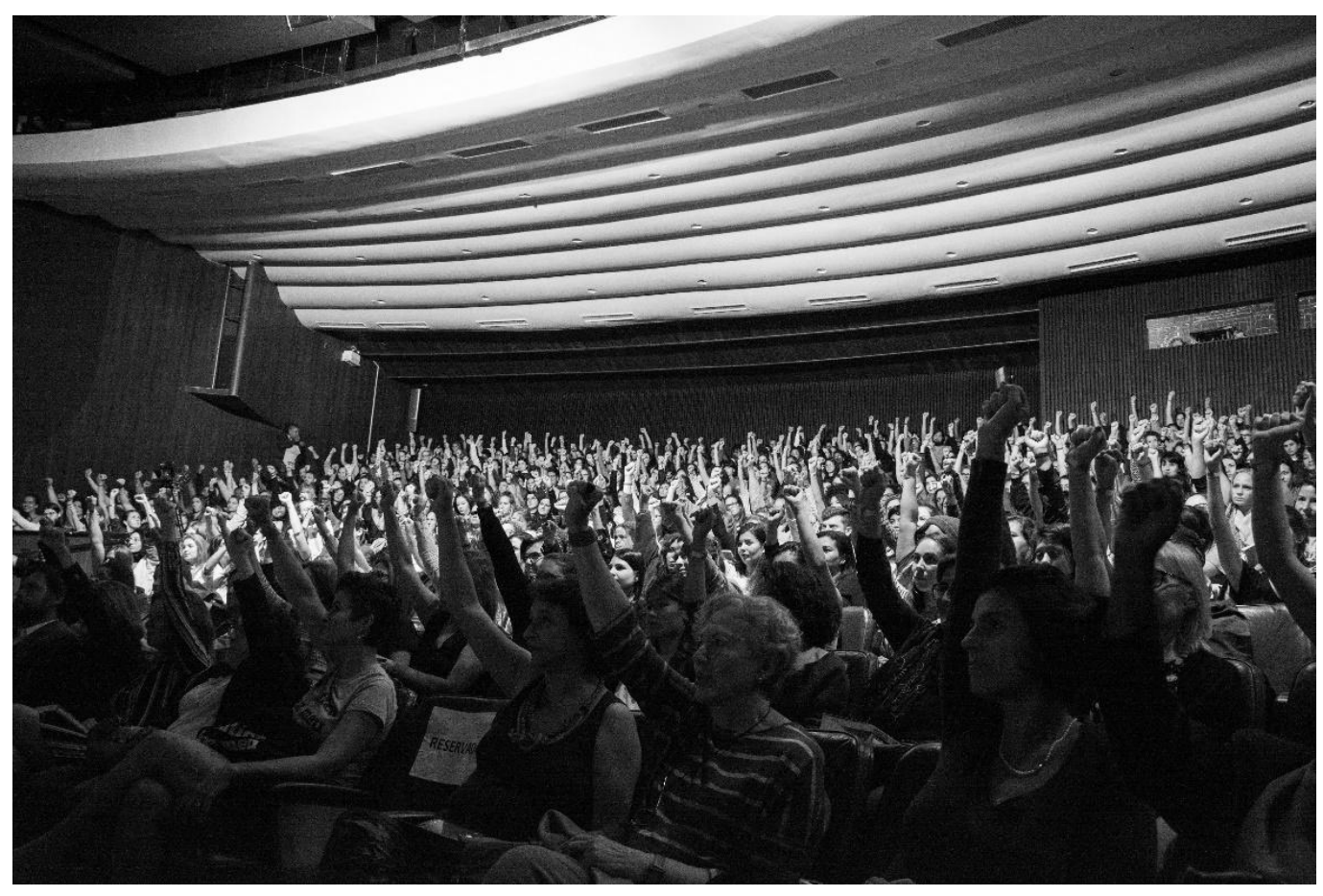

Punhos cerrados e resistência!

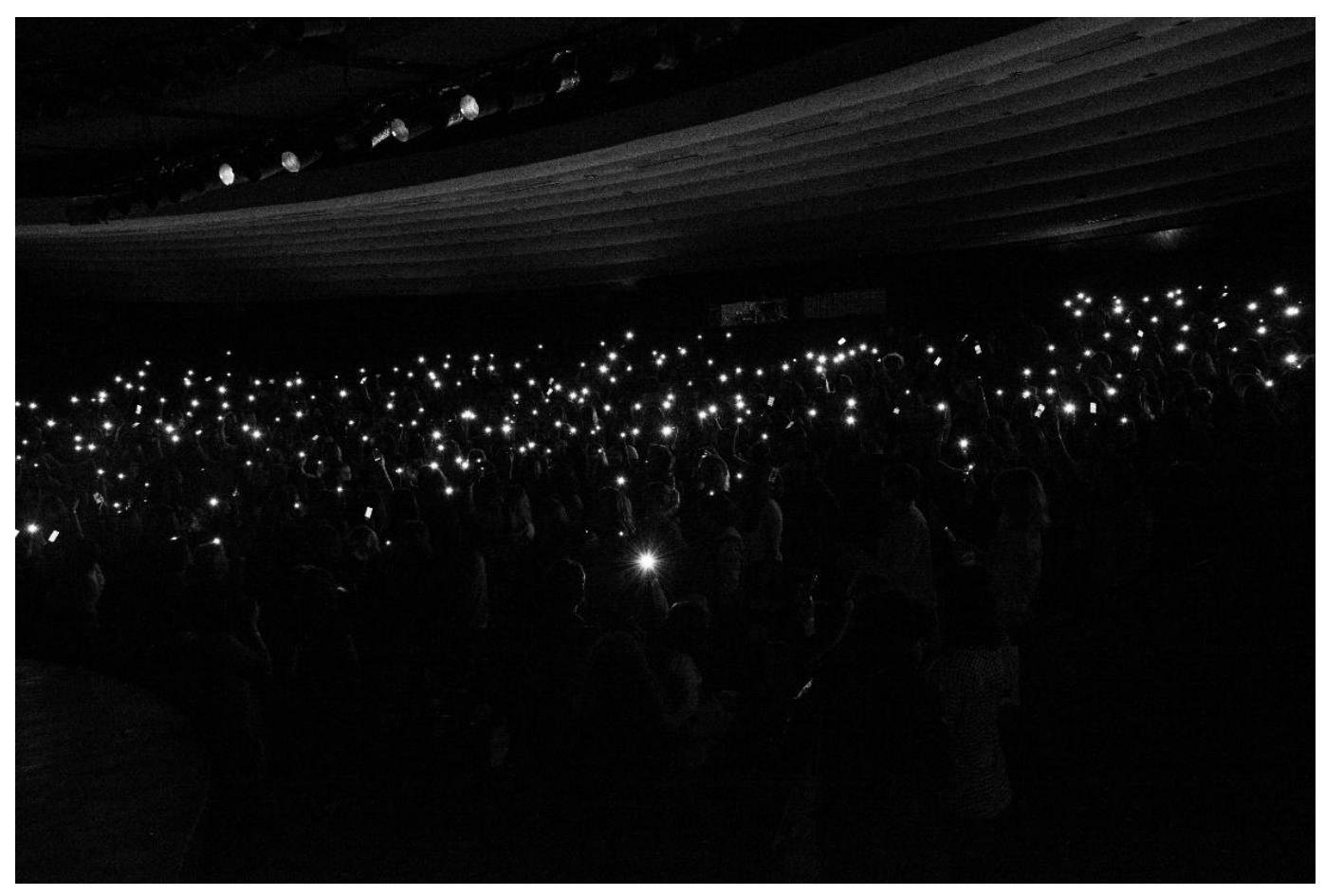

No Teatro da Reitoria, plateia interage durante a fala de abertura.

Rev. Sociologias Plurais, v. 5, n. 1, p. 41-51, jul. 2019 


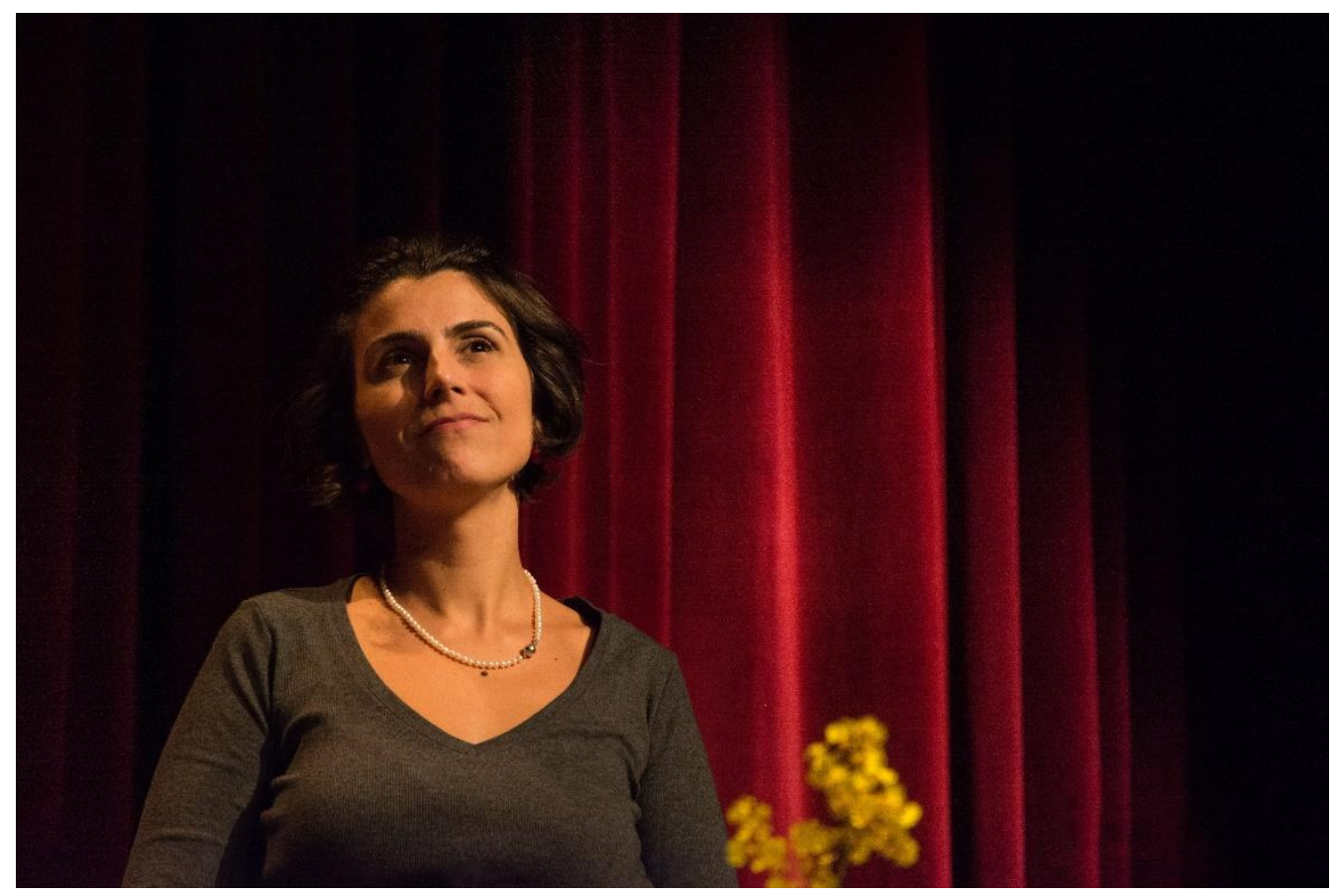

Manuela D’Ávila.

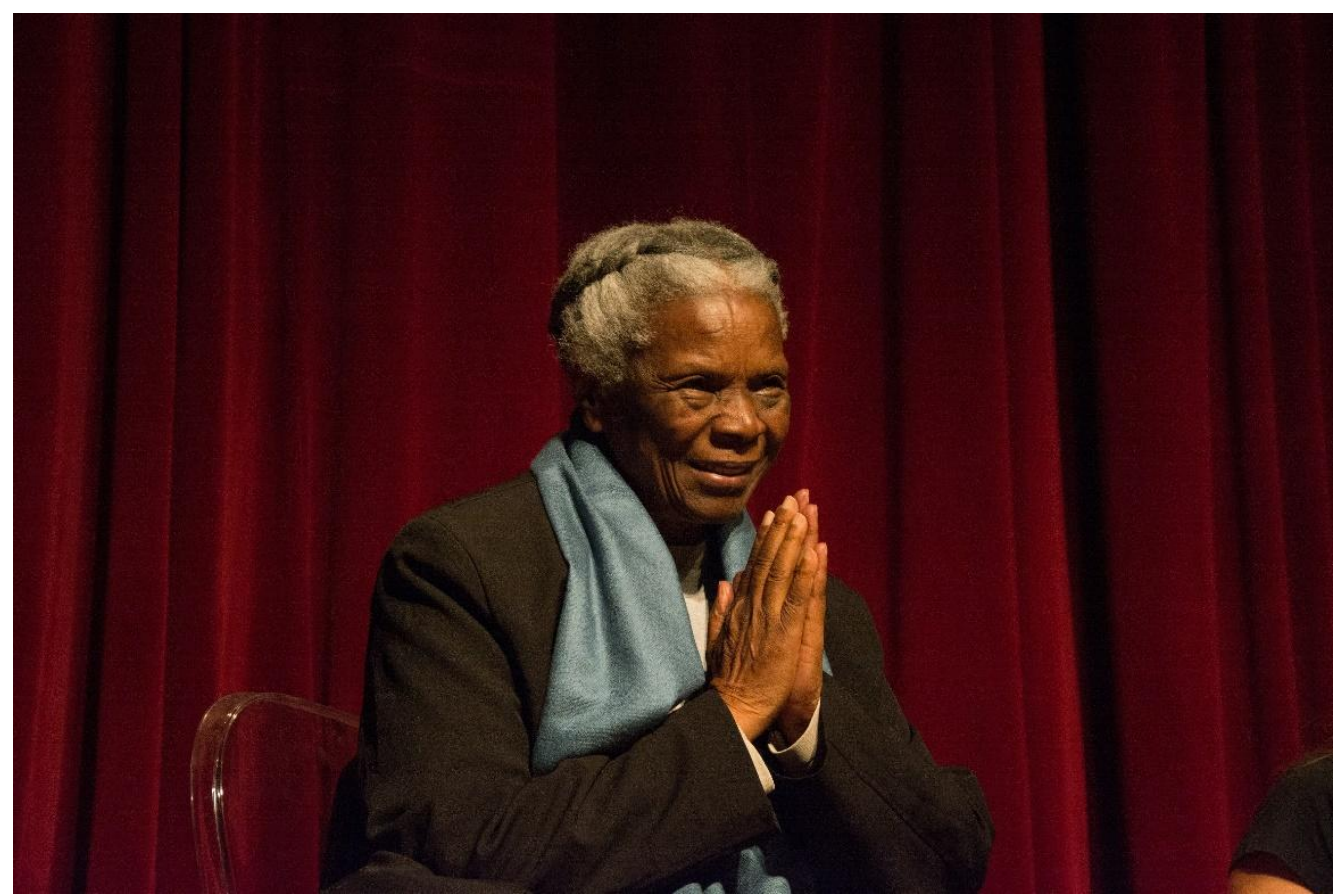

Diva Guimarães.

Rev. Sociologias Plurais, v. 5, n. 1, p. 41-51, jul. 2019 


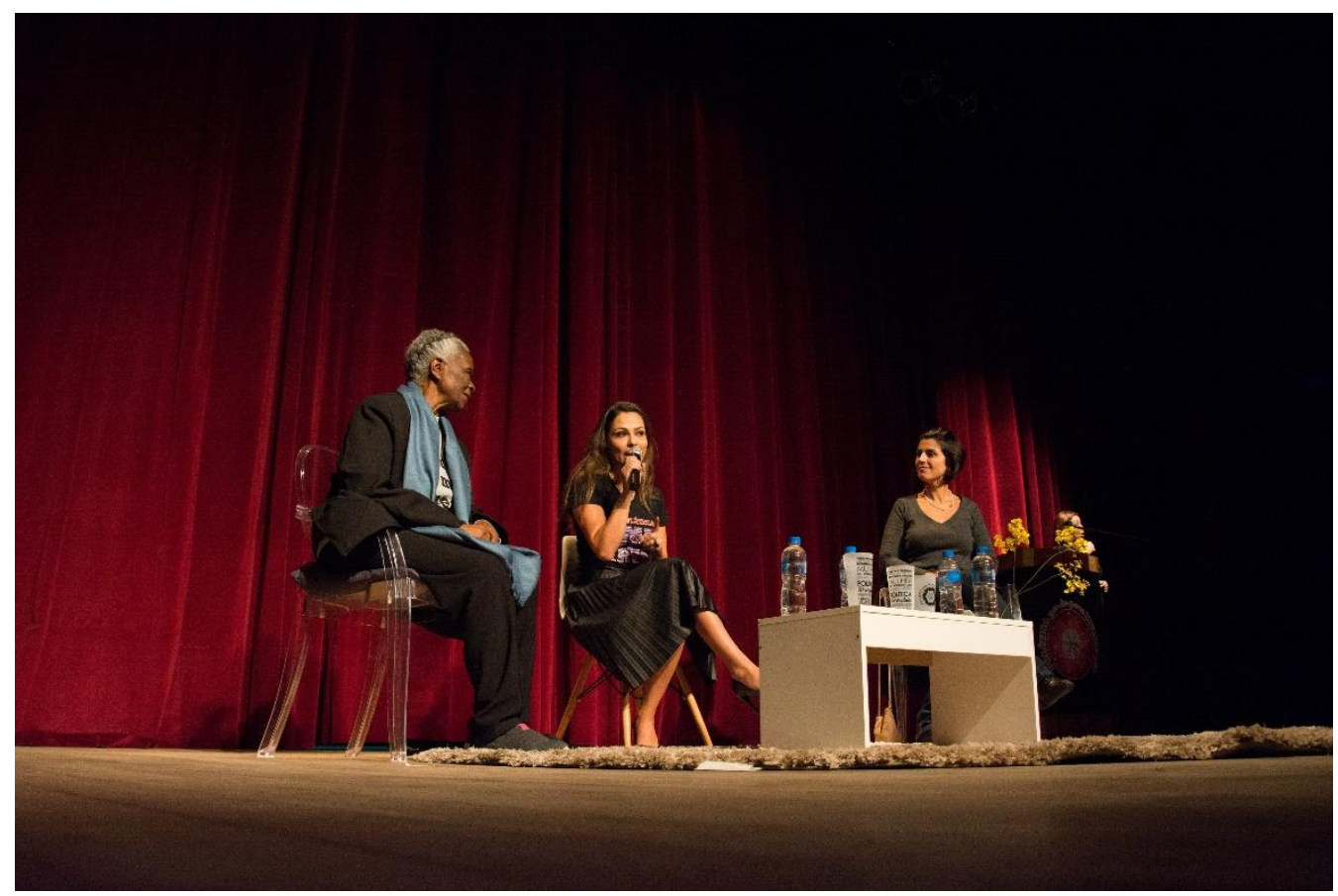

Começa o evento: Diva Guimarães, Ana Vieira e Manuela D’Ávila.

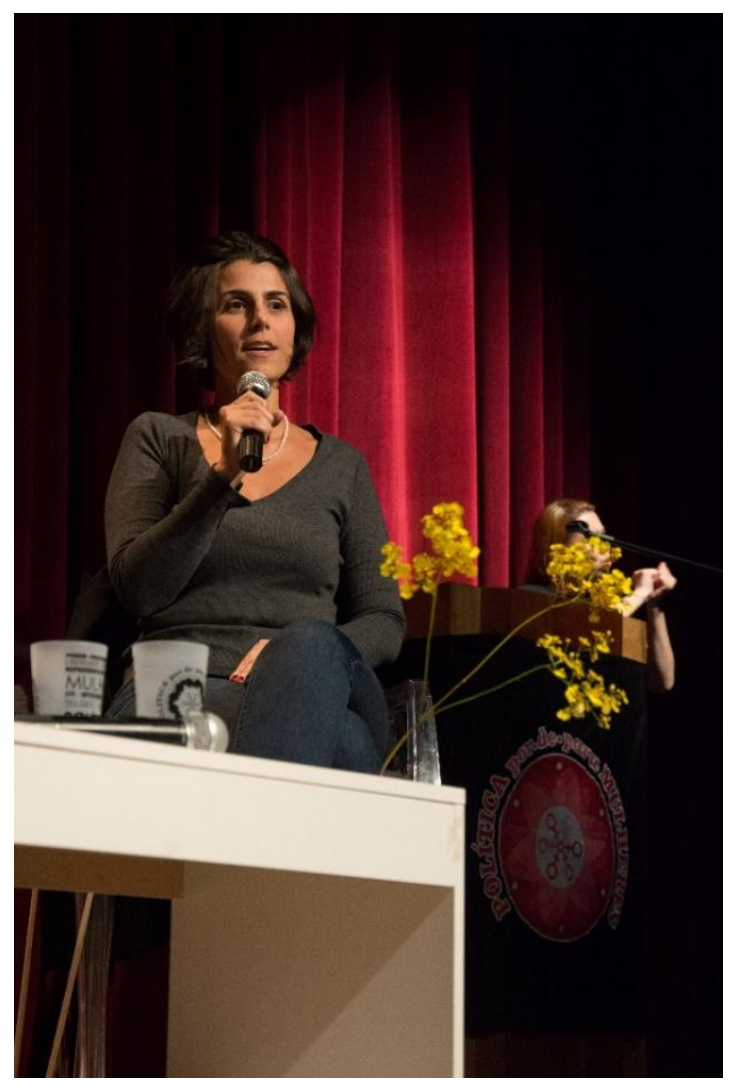

Em sua

comunicação,

Manuela fala sobre

as relações entre o

capitalismo e a

exploração de

mulheres. 


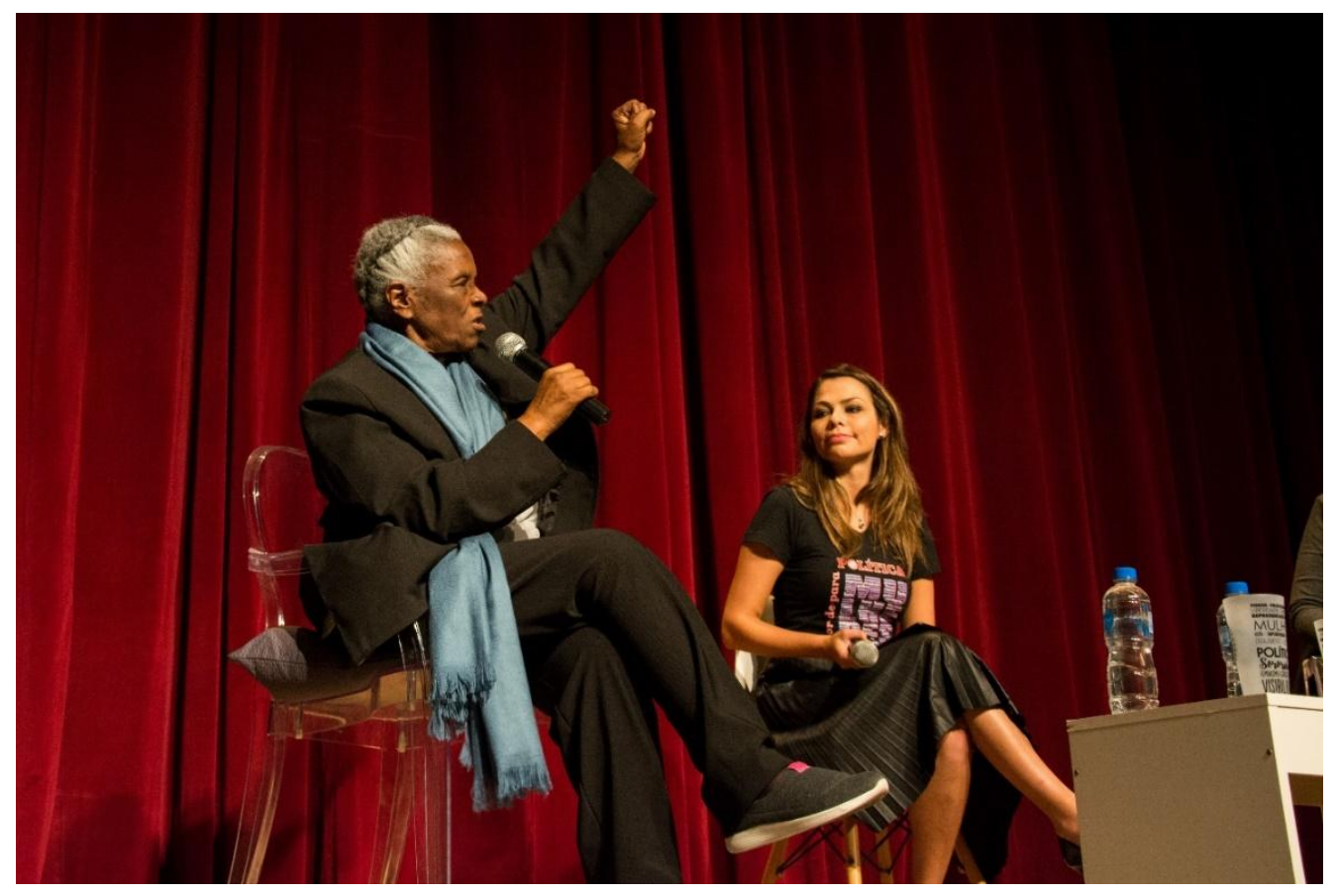

"Sou mulher e sou negra": Diva Guimarães.

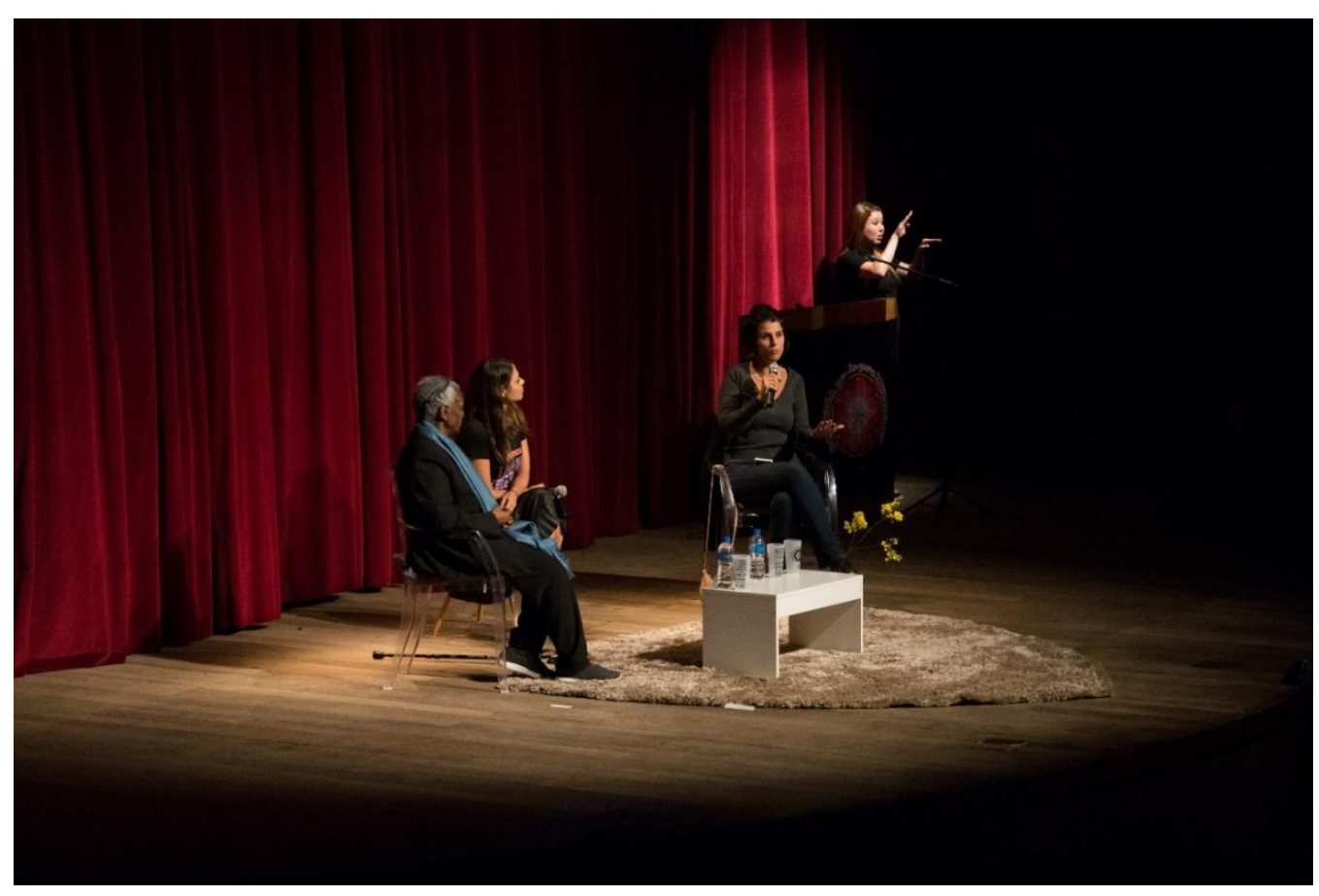

Mulheres e política.

Rev. Sociologias Plurais, v. 5, n. 1, p. 41-51, jul. 2019 


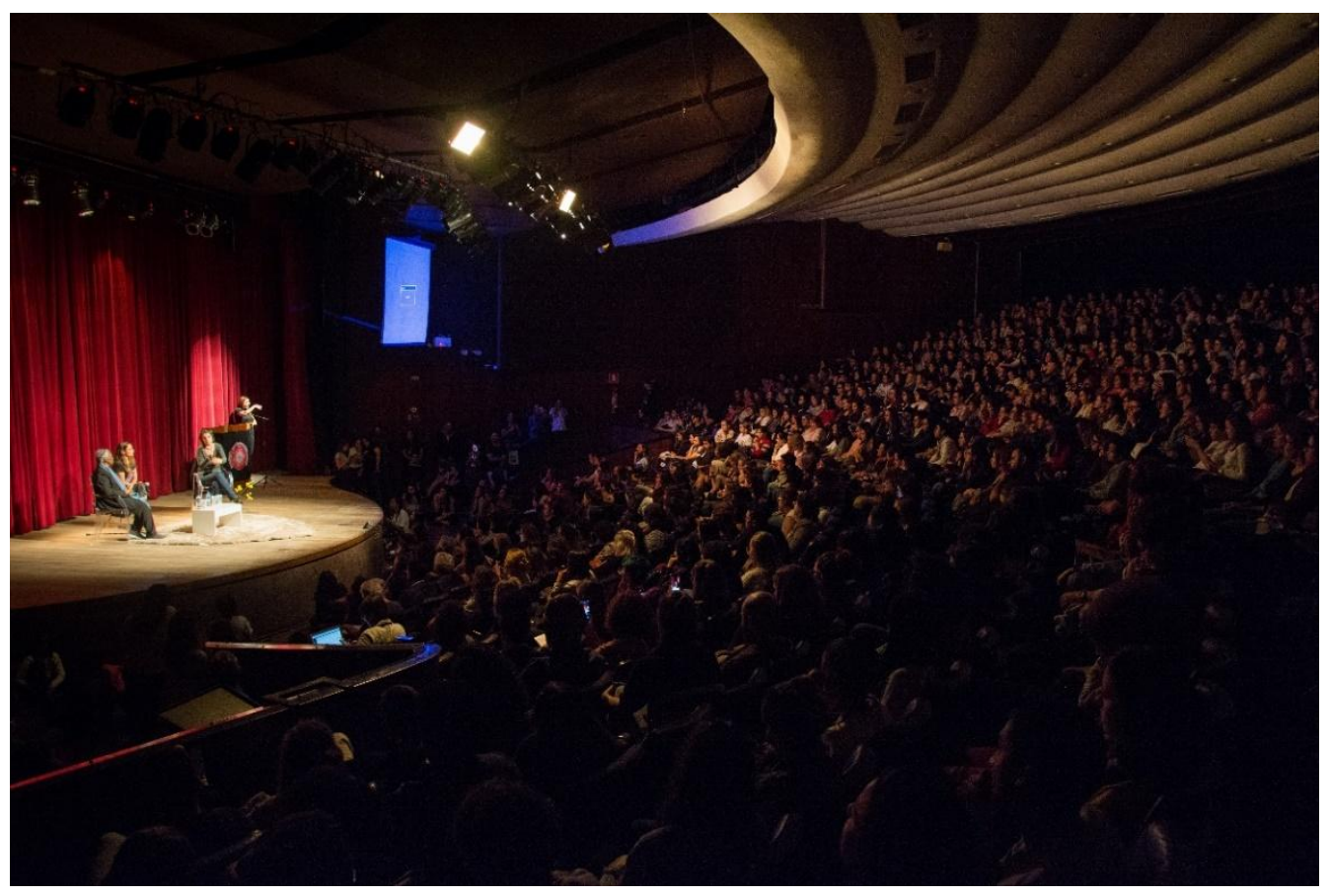

Teatro da Reitoria da UFPR lotado no lançamento do livro Gênero e Resistência.

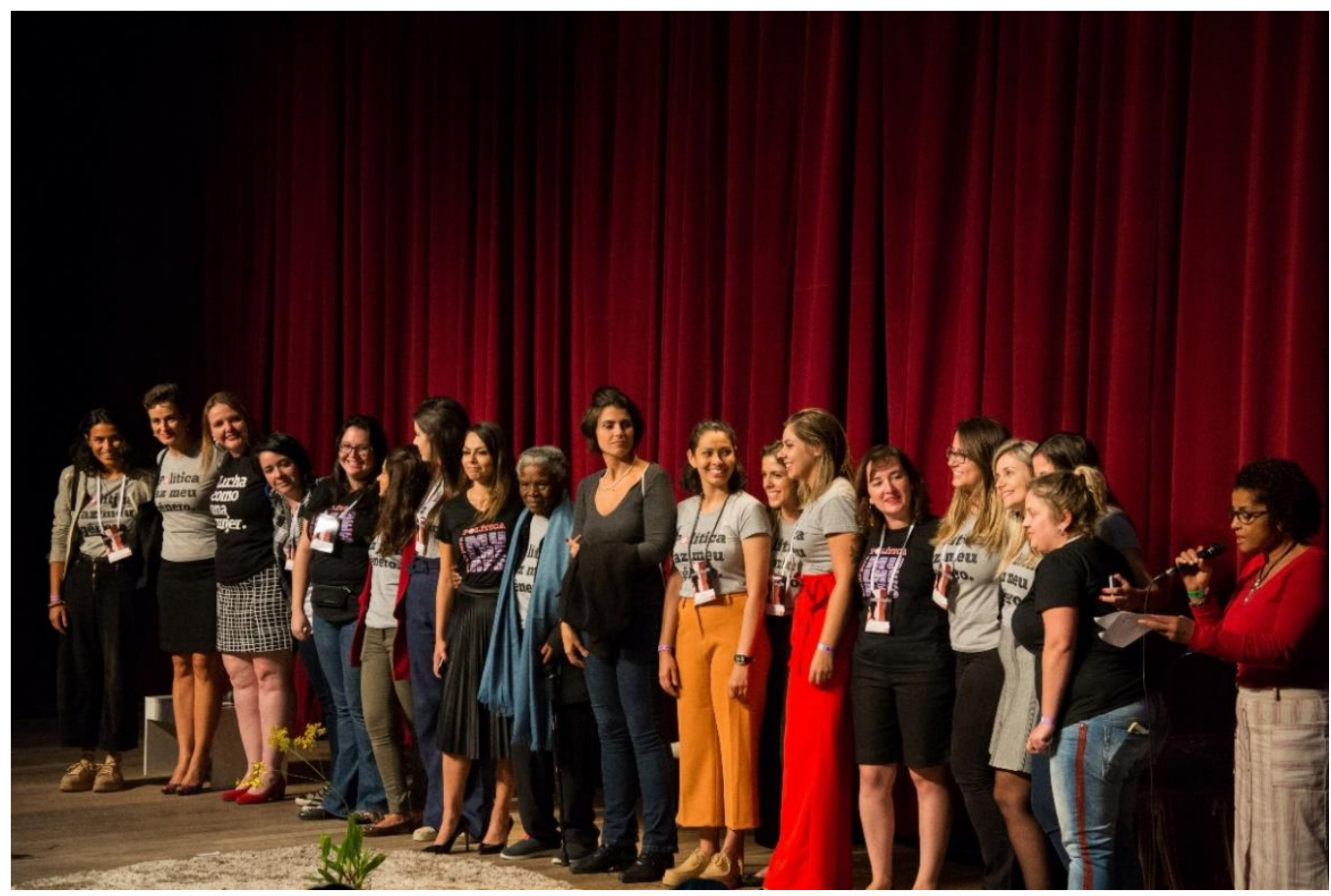

As mulheres que tornaram o evento possível. 


\section{FICHA TÉCNICA}

\section{Concepção}

Comissão Executiva Editorial

\section{Curadoria}

Henrique da Costa Valério Quagliato

Ramiro Gabriel Garcia

\section{Montagem}

Henrique da Costa Valério Quagliato

Patrícia dos Santos Dotti do Prado

Ramiro Gabriel Garcia

Fotografias

Ramiro Gabriel Garcia 